\title{
Cause Analysis of Turbine Shaft Ultrasonic Flaw Detection Disqualification
}

\author{
Wang Yongsheng ${ }^{1}$, Sun Shengyu ${ }^{1}$, Sun Xin ${ }^{2}$, Guo Libo $^{3}$ \\ ${ }^{1}$ Department of Chief Engineer's Office, Dongbei Special Steel Group, Dalian, China \\ ${ }^{2}$ ESR Plant of Dongbei Special Steel Group, Dalian, China \\ ${ }^{3}$ Central Laboratory of Dongbei Special Steel Group, Dalian, China
}

Email address:

13478595236@163.com (Wang Yongsheng)

\section{To cite this article:}

Wang Yongsheng, Sun Shengyu, Sun Xin, Guo Libo. Cause Analysis of Turbine Shaft Ultrasonic Flaw Detection Disqualification. American Journal of Mechanical and Materials Engineering. Vol. 3, No. 1, 2019, pp. 20-24. doi: 10.11648/j.ajmme.20190301.13

Received: November 20, 2018; Accepted: May 27, 2019; Published: June 18, 2019

\begin{abstract}
Heavy forging is a kind of large or deformed-size forge, used on marine, roller or power station roter. etc, which are fabricated by free forging or hydraulic compressor. The turbine shaft products, steel grade ASTM668E, rejected during ultrasonic inspection. Aiming at the problem of ultrasonic flaw detection disqualification, through Positioning saw cutting, the macroscopic test, SEM and Micrographic examination are taken out. The main cause of the disqualification were found out. The results show that, because of the exist of unbalance crystallization, highly grade general loosen happened in the cycle area, which cause the energy of ultrasonic are weakened a lot, then lead to the central quality of the forging cannot be detected clearly. What's more, the manganese sulfide precipitated at the grain boundary because of the selective crystallization occurs in the central of the ingot. The tensile stress on the interface between steel and inclusion separate the steel, caused the cracks which couldn't be welded as the plastic deformation happened in forging press, then cause the cracks. Reduce the molten steel's overheat and the freezing time can improve the defect of general loosen and the gartering of low-melting ingredients. Increase the compression ratio can take out too in the hot work process to solve the problem.
\end{abstract}

Keywords: Heavy Forging, ASTM668E, UT, General Loosen, Manganese Sulfide

\section{Research Background}

Generally, heavy forging is a kind of large or deformed-size forge, used on marine, roller or power station roter. etc, which are fabricated by free forging or hydraulic compressor, it's nominal pressure more than $1000 \mathrm{MN}$ [1]. The ingot are founded by bottom pouring or vacuum cast, and the applications are critical, the processing parameter is significant. What's more important, the forge is the products that contribute a high added value for metal presswork. The usually causes of heavy forging disqualifications are: internal macro holes, large-scale inclusion, and the ultrasonic test over proof cause by coarse crystal. [2]

Hydraulic electro is one of a major energy source for the cleanness and reproducible. The critical part on the power station, turbine shaft, made by steel grade ASTM668E [3], the process flow, which external diameter $800 \mathrm{~mm}$ is: Blast furnace $\rightarrow$ Converter $\rightarrow$ Ladle furnace refine $\rightarrow$ RHdegas $\rightarrow$ Ingot cast(37tons) $\rightarrow$ Free forging(8000MN press work) $\rightarrow$ Heat treatment $\rightarrow$ Rough finish.

The products rejected during ultrasonic inspection, a fatal disqualification exist in a cycle area, and the energy of ultrasonic are weakened a lot, no reflection accept in any angle nor any position.

The analyze are taken out aiming at correction and precaution means.

\section{Physical and Chemical Inspection}

\subsection{Positioning Cutting and Macroscopic Test}

Through saw cutting on ultrasonic inspection disqualification, the defect expose on macro structure sample, the cycle area, seen figure 1. What's more, dense cracks appear on the sample center. The partial enlarged drawing seen figure 2 . 


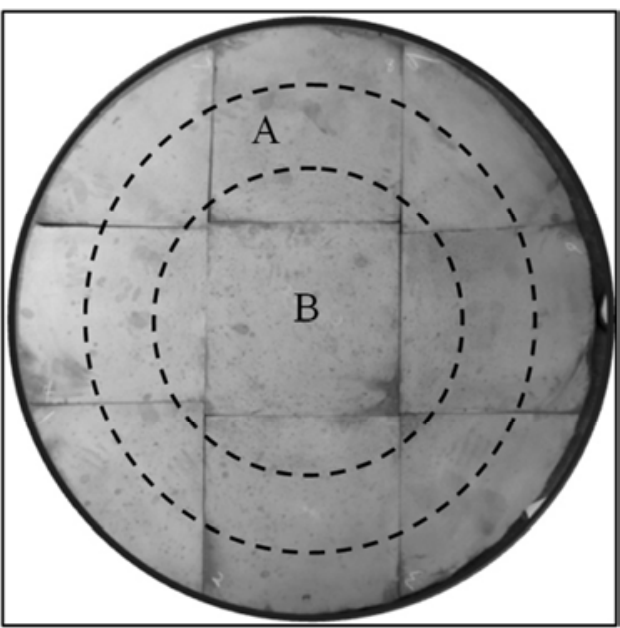

Figure 1. Macro morphology of the disqualification.

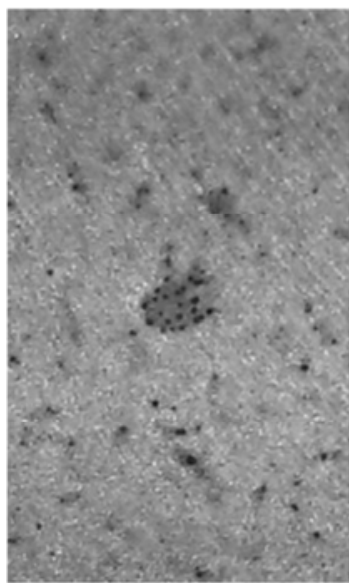

(1)

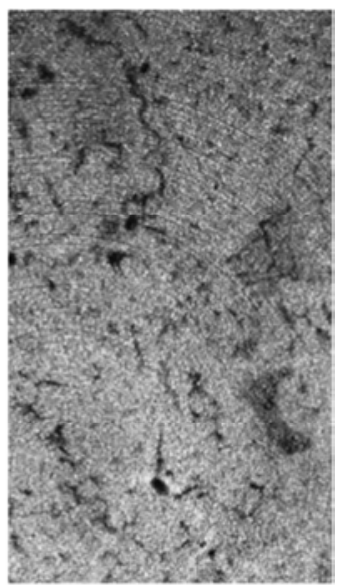

(2)

Figure 2. Magnify of the part.

\subsection{Fracture and SEM Analysis}

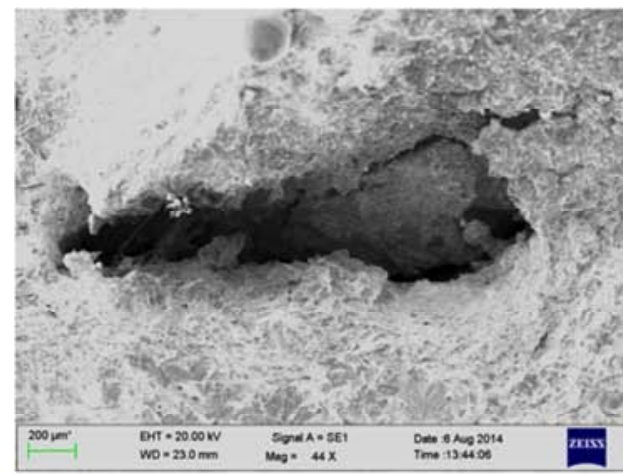

(1) Fracture morphology

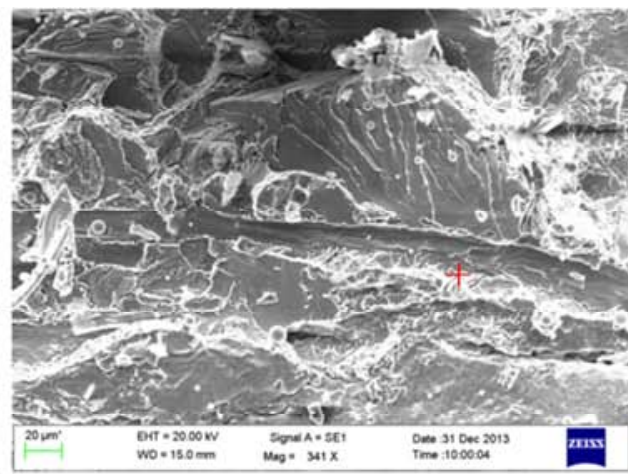

(2) Crack propagation morphology

\begin{tabular}{c|c|c}
\hline elements & $\begin{array}{c}\text { percentage } \\
\text { in weight }\end{array}$ & $\begin{array}{c}\text { percentage } \\
\text { in atom }\end{array}$ \\
\hline $\mathrm{C} \mathrm{K}$ & 31.90 & 63.39 \\
\hline $\mathrm{S} \mathrm{K}$ & 22.90 & 17.04 \\
\hline $\mathrm{Mn} \mathrm{K}$ & 35.73 & 15.52 \\
\hline Fe K & 9.47 & 4.05 \\
\hline Total & 100.00 & 100.00 \\
\hline
\end{tabular}

(3) EDS analysis result of the fracture

Figure 3. SEM morphology and EDS analysis results.

The samples cut from position A and B on macro structure in figure 1 , dimension $200 \mathrm{~mm} \times 20 \mathrm{~mm} \times 15 \mathrm{~mm}$. A notch groove, depth $3 \mathrm{~mm}$, width $3 \mathrm{~mm}$, cut on the sample back, and the drop test is taken out. The fracture and the SEM pattern seen figure 3 .

\subsection{Metallographic Analysis}

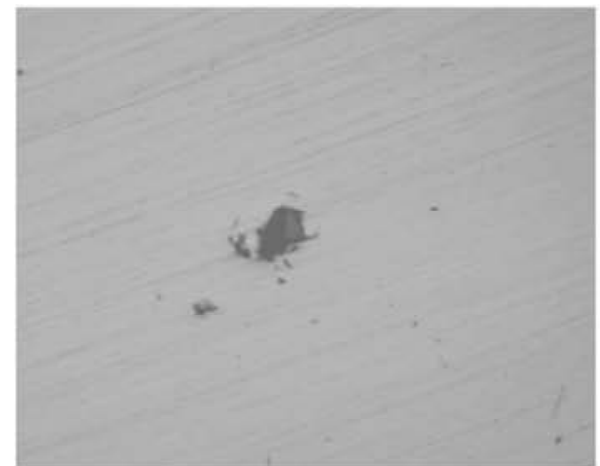

(1) Micro hole morphology

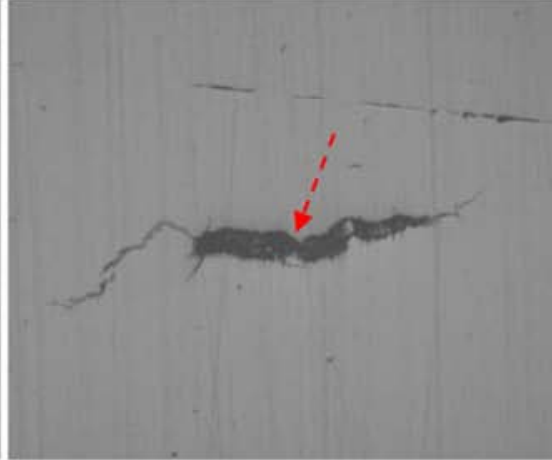

(2) Stress crack morphology

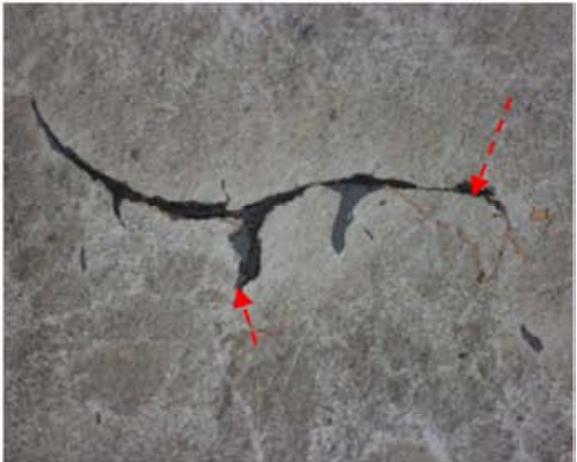

(3) The non-metallic inclusion in crack

Figure 4. The microscopy analyse, $100 \times$.

Metallographic sample made from position A in figure 1, and the stress crack, the non-metallic inclusion in the crack of position B seen figure 4 (4\% natal). 


\section{Analysis}

\subsection{Ultrasonic Test and Macro Structure Analysis}

Ultrasonic test indicate that, the defect are type of head-to-tail (full-length of the forge), located in a circle area. Generally, such defects are most probably caused by ingot defect. Ultrasonic test predicate the pattern and position which approved by positioning cutting analyze. The 4.0 grade general loosen is found according to GB/T1979-2001. After partial enlarged of general loosen, the minor-sized micro holes build-up the defects (figure 2).

The ultrasonic are reflected on the interface of defect after entrance into the forge, the depth, size and characters displayed on screen then. The dense micro-sized holes discovered during positioning cut could cause the ultrasonic scatter off, and fade down, what result in no reflection accepts in any angles nor any position eventually.

\subsection{Fracture Analyses}

The irregularly holes discovered on the fracture, has a rough interface and direction-free. What's more, the manganese sulfide inclusion-band appears on the cleavage fracture after energy spectrum analysis (sees in figure 3 ).

\subsection{Micro Structure Analyses}

During the transverse metallographic examination of the defect, light gray inclusion attach on the interface of the micro holes and cracks, the titanium nitride, which represent golden color found too, and obviously stress cracks appears either(figure 4).

\subsection{Discuss}

\subsubsection{The Pattern and Formation of General Loosen}

The macro structure of the forge present remarkable feature of general loosen, which have a obvious gathering character of micro-size holes and micro cracks. The ranking guide of the defect is the numbers, size, and distribution of the spots, the stage of fir-tree crystal must be considered. [4]

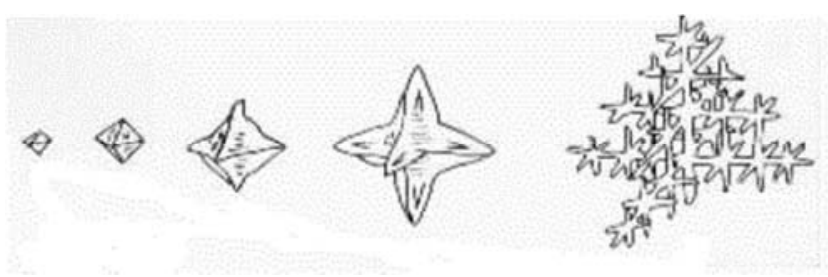

Figure 5. The growth of fir-tree crystal.

After ingot cast, the melt steel freezing from ecto-entad, bottom to top as the temperature reduce. Because the exits of unbalance crystallization, the pre-welding area growth up as fir-tree type, a lot of micro gap appears between major and secondary interdendritic branches as different crystal cell meet each other(figure 5). The low-melting components, gas and nonmetallic inclusions gathering at this area, which could corrosion easily by acid when macro structure exam are taken out, then flake off during flush, what's reflect the characters above.

The disqualification forge analyzed above is fabricated by large-sized ingot, the surface temperature reduced quickly, and the crystal couldn't growth sufficiency, the micro-holes are limited. As the welding goes in, the gradient of melt steel temperature reduced, and the freezing happens in a width range, the fir-tree crystal growth sufficiency, and many secondary branches appears among major ones, the micro-holes increase a lot(as figure 5 profile), what's provide gathering necessary factors of low-melting components, gas and nonmetallic inclusions, finally cycle defect in figure 1 occurs.

\subsubsection{Non-metallic Inclusions in Steel}

Nonmetallic inclusions usually refer to oxides, sulphides, and some high melting point nitrides, etc. The main source of nonmetallic inclusions is that the equilibrium of oxygen, sulfur, nitrogen and liquid steel moves with the decrease of temperature during the condensation process of molten steel, which results in the increase of equilibrium constants of various compounds of oxygen, sulfur and nitrogen, thus forming various nonmetallic compounds. [5]

According to the chemical composition, the nonmetallic inclusions in steel can be divided into:

1. oxides, for example $\mathrm{FeO}, \mathrm{MnO}, \mathrm{SiO}_{2}, \mathrm{AI}_{2} \mathrm{O}_{3}, \mathrm{CaO}$, etc.

2. sulphides, for example $\mathrm{FeO}, \mathrm{MnO}, \mathrm{SiO}_{2}, \mathrm{AI}_{2} \mathrm{O}_{3}, \mathrm{CaO}$, etc.

3. carbonitride, for example $\mathrm{AlN}$, TiN, $\mathrm{Ti}(\mathrm{CN}), \mathrm{V}(\mathrm{CN})$, $\mathrm{Nb}(\mathrm{CN})$, etc

4. phosphide, for example $\mathrm{FeP}_{3}$, etc. [6]

According to the ductility of inclusions, the nonmetallic inclusions in steel can be divided into:

(1) Plastic inclusion: which can be extended into strips along the processing direction during hot working. for example $\mathrm{FeO}, \mathrm{CaO}, \mathrm{AL}_{2} \mathrm{O}_{3}, \mathrm{MnO}, \mathrm{MnS}, \mathrm{CaS}$, silicate, etc.

(2) Brittle inclusion: This cannot be deformed in hot working, but distributed to chain-form along the processing direction, $\mathrm{SiO}_{2}$ for example.

(3) Punctate non-deformable inclusion (spherical inclusion): Inclusions that maintain the original spherical type in hot working. Corundum, spinel, calcium aluminate type, for example.

\subsubsection{Manganese Sulfide in Steel}

Sulfide usually seen as harmful ingredient in steel beside free-cutting steel, the eutectic between Fe and oxygen easily gathering at grain boundary, what's melting could cause cracks when hot-forming happened[7].

Being as deoxidize or alloying element, the special steel contains manganese more or less in percent, and manganese can easily combined with Sulfide, so Manganese sulfide is one of the most common nonmetallic inclusions in steel, even can be seen as normal composition of steel. The melting point of Manganese sulfide is $1610^{\circ} \mathrm{C}$, as the degree of superheat decreased, Manganese sulfide precipitated at the grain boundary. 
During rolling, the deformation of most oxide inclusions is lower than MnSinclusions, Therefore, in highplasticity carbon steels and low alloy structural steels, the influence of sulfides is much greater than oxide inclusions. [8]

\subsubsection{General Rules of Formation of Sulphide Inclusions}

Although we have used advanced metallurgical technology to remove the Sulfur element in iron-making process, there are always sulphide residues in the steel, and the sulfur content can only be removed to about the mass fraction at most $2 \times 10^{-6}[9]$.

Fredriksson et al. analyses the formation of manganese sulphide, it can be divided to four different reactions[10]. Sulfur in molten iron can be dissolved indefinitely, but the solubility of sulfur is very low in solid iron. The maximum solubility of sulfur in $\delta$-Fe is $0.15 \%$ At $1365^{\circ} \mathrm{C}$, the maximum solubility of sulfur in $\gamma$-fe is $0.06 \%, 0.018 \%$ at $913^{\circ} \mathrm{C}$ and $0.007 \%$ in $\gamma$-fe. Therefore, it must be precipitated in the form of sulfide inclusions, which dissolved in iron at high temperature, along with the temperature lowering of molten iron and the solidification of molten iron. The eutectic point temperature of $\mathrm{Fe}-\mathrm{Fes}$ is $988^{\circ} \mathrm{C}$, which is far lower than that of pure iron at $1535^{\circ} \mathrm{C}$. The Fes inclusion precipitates at the grain boundary because of the selective crystallization of ingot.

\subsubsection{Effect of Non-metallic Inclusions on Mechanical Properties of Steel}

As a heterogeneous phase, because of its poor binding ability with the matrix, inclusions inevitably form microcracks at the grain boundary, resulting in stress concentration. The effect of non-metallic inclusions on plasticity is that the elongation and section shrinkage of steel are reduced. The deformation capacity and expansion coefficient of inclusions in steel are the important factors affecting the fatigue properties of the matrix. In addition, the size of inclusions, which are the source of fatigue cracks, varies with the depth of the inclusions from the surface of the steel. [10]

It has long been recognized that inclusions play a decisive role in ductile fracture. It can be said that the fibrous fracture is almost entirely caused by inclusions in the material. Increasing the volume fraction of non-metallic inclusions, whether sulfide or oxide inclusions, will reduce the plasticity of materials before fracture and damage the formability of steel.

The precipitated phase of manganese sulfide almost appears in most steels, which plays a decisive role in the influence of steel properties. Especially, it has a great influence on the ductility of steel at high temperature. The transverse ductility of ingot decreases due to the anisotropy of manganese sulfide during hot rolling. [11]

In the hot working process, the influence of easily deformed inclusions is great. With the increase of banded inclusions, mainly sulfides, the transverse section shrinkage rate and impact work decrease obviously. Because of the low melting point, eutectic crystals $\left(\mathrm{Fe}+\mathrm{FeS} 988^{\circ} \mathrm{C}, \mathrm{FeS}+\mathrm{FeO}\right.$ $940^{\circ} \mathrm{C}$ ), precipitated along the grain boundary of primary grain, melted during hot working, which resulted in cracking of steel[12].

It is now clear that large inclusions are more likely to form voids than small ones [13], when the material is loaded, the ductility of the sulfide inclusion is larger than that of the matrix, so there is a long and narrow slip band in the sulfide inclusion due to plane slip. The dislocation of these slip bands is blocked on the interface of inclusions and matrix resulting in the stress concentration at the interface so that the inclusions and the matrix are finally removed here to form voids.

As the plastic deformation happened in forging press, the internal defects of ingot can be welded in specific grade. The generation of cracks has three forms: the micro holes occurs and growth beside inclusions; the inclusion stripping, and the cracks expansion on interface; the cracks occurs at the grain boundary, then expansions. Because the thermal expansion coefficient of Manganese sulfide is greater than steel, so its' shrinking faster, and gap happened in 1.1 percent when the steel freezing. The tensile stress on the interface between steel and inclusion separate the steel, caused the cracks which couldn't be welded [14], The highly deformed inclusions cause metal lateral displacement, which can produce tensile stress in the metal above and below the inclusions, resulting in tension cracks in the metal, and cavitation under the action of very small stress [15], figure 4 above proved this.

\section{Conclusion and Suggests}

The reason of the disqualification is the cracks caused by the highly grade general loosen and gathering of central inclusions.

Reduce the molten steel's overheat and the freezing time can improve the defect of general loosen and the gartering of low-melting ingredients. Increase the compression ratio can take out too in the hot work process.

\section{References}

[1] YAO Ze-kun. Forging Technology [M]. XI AN: Press of Northwestern Polytechnic University, 1998: 77.

[2] MA Qing-xian, et al. Study on Mechanism of Defects Originated from Inclusions in Processes of Heavy Forgings, [J]. China Mechanical Engineering. 2001, 12 (8):943-945.

[3] DONG Lan-feng, ZhongYue-xian, et al. Research on the Dynamic Recrystallization Behavior of 20SiMn, [J]. China Mechanical Engineering. 2008, 19 (10):1245-1249.

[4] GB/T1979-2001, Grading Diagrams for Macrostructure and Defect of structural steels [S].

[5] LI Dai-zhong. Nonmetallic Inclusion in Steel [M], Peking: Science Press, 1983.

[6] SHEN Cai-fang, SUN She-cheng, CHEN Jian-bin, et al. Technology and equipment of EAF Steel making [M], Peking: Metallurgical industry Press, 2001. 
[7] LIU Xue. Precipitation Behavior of MnS Inclusion in the steel [D]. Thesis for Master's Degree of Northeastern University, June 2012.

[8] Г. M. Iczkovits. Deoxidation and Modifying Technology of Inclusion in Steel [M], Peking: Metallurgical industry Press, 1986.

[9] Luu W C, Wu I K. Effects of sulfide inclusion on hydrogentmnsport in steels [J], Materials Letters, 1995, 24 (2):175-179.

[10] Li Wei-liao. Nonmetallic Inclusion in Steel [M], Peking: Science Press, 1988.

[11] Diederichs R, Bite R, Pariser G, et al. Modelling of manganese sulphide formation during solidification, Part i: Correlation of solidification and MnS formation [J], Steel Research International, 2006, 77 (4):256-264.
[12] XU Jian-bing, YU Ji-xing, SU Kai. The Effect of Sulphide on Fatigue Crack Initiation of Cold Ring-Rolling Mandrel [J], China Metal Forming Equipment \& Manufacturing Technology, 2006 (4):80-81.

[13] YANG RANG. Lectures foundation of High Strength Low Alloy(HSLA) Steels II [M], Peking: China Metallurgy society, 1986.

[14] REN Xue-chong, LI Gao-yang, et al. Effects of Inclusions and Grain Size on Impact Toughness of a Cleaning Wheel steel at Room Temperature [J]. PTCA (PART A: PHYS. TEST), 2012, $48(4): 207-212$.

[15] XIA Zhi-xin, YE Wen-bing, YANG Zhuo-yue, et al. Effect of Morphology of MnS Inclusions on Toughness of Ultra-High Strength Steel Produced by Different Smelting Processes [J], Journal of Iron and Steel Research, 2009, 21 (3):13-14. 